\title{
Compression of pulsed electron beams for material tests
}

\author{
Alexander S. Metel* \\ Moscow State University of Technology "STANKIN", 1 Vadkovsky per., Moscow GSP-4, 127055, Russian Federation
}

Received: 1 September 2017 / Accepted: 20 November 2017

\begin{abstract}
In order to strengthen the surface of machine parts and investigate behavior of their materials exposed to highly dense energy fluxes an electron gun has been developed, which produces the pulsed beams of electrons with the energy up to $300 \mathrm{keV}$ and the current up to $250 \mathrm{~A}$ at the pulse width of 100-200 $\mu$ s. Electrons are extracted into the accelerating gap from the hollow cathode glow discharge plasma through a flat or a spherical grid. The flat grid produces 16-cm-diameter beams with the density of transported per one pulse energy not exceeding $15 \mathrm{~J} \cdot \mathrm{cm}^{-2}$, which is not enough even for the surface hardening. The spherical grid enables compression of the beams and regulation of the energy density from $15 \mathrm{~J} \cdot \mathrm{cm}^{-2}$ up to $15 \mathrm{~kJ} \cdot \mathrm{cm}^{-2}$, thus allowing hardening, pulsed melting of the machine part surface with the further high-speed recrystallization as well as an explosive ablation of the surface layer.
\end{abstract}

Keywords: Surface hardening / electron beam compression / surface melting / explosive ablation / material tests

\section{Introduction}

For the surface modification of various machine parts are widely used the low-pressure gas-discharge plasma and beams of accelerated ions [1], fast neutral atoms [2-5] and electrons $[6,7]$. In addition to the plasma generation, the low-pressure discharges can produce flows of metal atoms [8-15] and metal ions [16-21] for the synthesis on the product surface of the wear-resistant and anticorrosion coating, which greatly increase the useful life of the machine parts. Broad beams of ions and fast neutral gas atoms mixed with metal atoms can be used for the improvement of the coating properties [22-25]. Pulsed electron beams [6] can be used for metal surface hardening, melting or ablation. They can also melt the product surface layer and deposited on the product coatings of any other substances thus producing new alloys.

At the distance of $10 \mathrm{~cm}$ between the plane-parallel anode and the thermionic cathode with sufficient emissivity and accelerating voltage of $250 \mathrm{kV}$, density of the electron current in the accelerating gap amounts according to the Child-Langmuir law [26] to $j_{\mathrm{e}} \approx 3 \mathrm{~A} \cdot \mathrm{cm}^{-2}$, and the power density of $0.75 \mathrm{MW} \cdot \mathrm{cm}^{-2}$ on the anode surface allows transmission to the surface layer of the anode material within a $100-\mu$ s-wide pulse energy, whose density $w$ reaches tens of $\mathrm{J} \cdot \mathrm{cm}^{-2}$ per one pulse. At the pulse width

\footnotetext{
* e-mail: a.metelestankin.ru
}

of about $100 \mu \mathrm{s}$, the nature of the electron beam action on the metal surface is determined only by the energy density [27].

When instead of the thermionic cathode a plasma electron emitter is used, the gas pressure in the accelerating gap should be below the breakdown threshold determined by the Paschen curve. To avoid breakdowns at accelerating voltage of $100-300 \mathrm{kV}$, the pressure in the gap should be much lower than 0.1 Pa. However, when the area of the plasma emitter amounts to $200 \mathrm{~cm}^{2}$, the gas pressure in the accelerating gap is almost equal to the gas pressure in the plasma emitter. Therefore, it is necessary to produce the plasma emitter using a discharge at the gas pressure of about $0.01 \mathrm{~Pa}$.

It was found in [28] that in the hollow cathode glow discharge the lower limit of the operating pressure range can be reduced down to $0.01 \mathrm{~Pa}$. The hollow cathode plays a role of electrostatic trap $[29,30]$ for fast electrons emitted by the cathode surface and produced in the cathode sheath of the discharge. This paper is dedicated to the development of an electron gun based on the low-pressure hollow-cathode glow discharge producing for the surface modification of machine parts and material tests the broad pulsed beams.

\section{Experimental setup}

Figure 1a presents a schematic diagram of the experimental electron gun. Inside high-voltage feedthrough 1, which is installed on the upper flange of 0.8-m-diameter and 1-m-high 


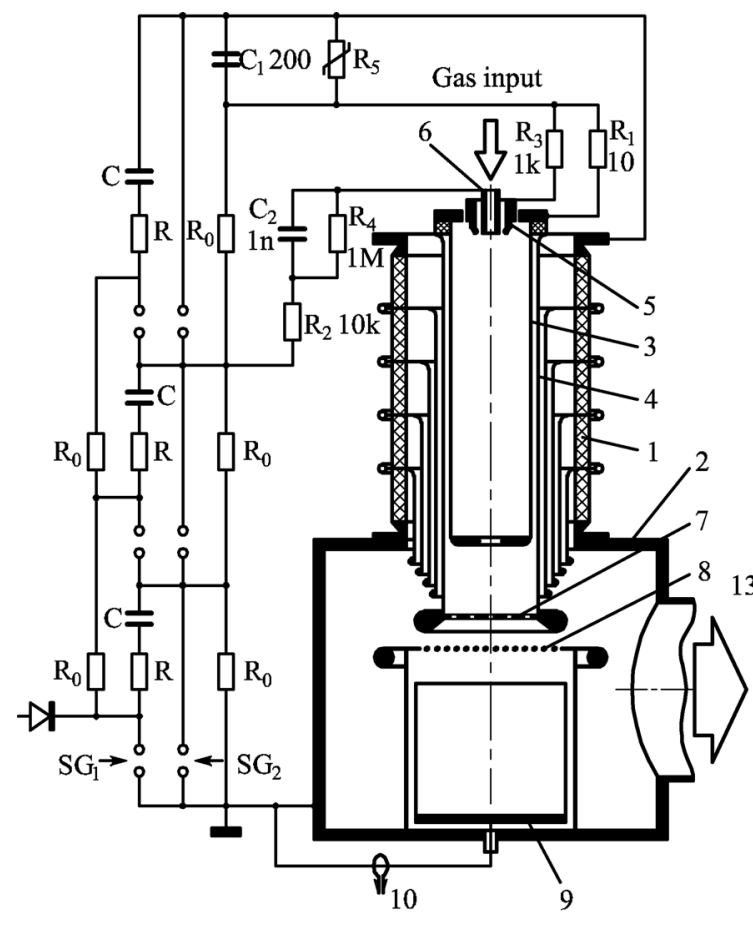

a

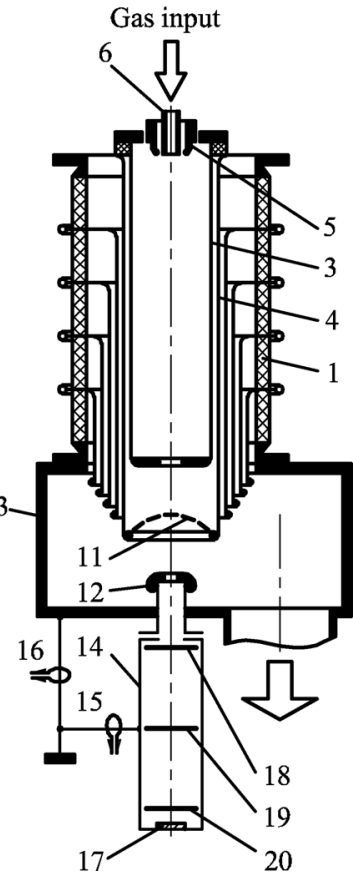

b

Fig. 1. Schematic diagram of the electron gun with flat (a) and spherical (b) grid (1) High-voltage feedthrough; (2) Vacuum chamber; (3) Hollow cathode; (4) Hollow anode; (5) Additional cathode; (6) Igniting electrode; (7) Flat grid; (8) Grounded anode; (9) Faraday cup; (10, 15, 16) - Rogovsky coils; (11) Spherical grid; (12) Spherical anode; (13) Modified chamber; (14) Hollow collector; (17) Substrate; (18, 19, 20) Foils.

vacuum chamber 2 , are mounted 18 -cm-diameter and 60-cmlong hollow cathode 3 as well as 20-cm-diameter and 80-cmlong hollow anode 4 . The upper end of the cathode is covered by a flange with additional cathode 5 and igniting electrode 6 . Gas is supplied to the hollow cathode through a central hole of the igniting electrode. On the upper flange there is a needle-valve to adjust the gas flow rate (not shown in Fig. 1a). The lower end of the hollow cathode is covered by a diaphragm with a 6-cm-diameter central orifice.

The lower end of the hollow anode is covered by an accelerating electrode with flat 16-cm-diameter emissive grid 7. The diameter of the grid orifices is equal to $3 \mathrm{~mm}$, and the distance between their centers amounts to $4 \mathrm{~mm}$. At a distance of $10 \mathrm{~cm}$ from the grid is installed grounded 50 -cm-high hollow anode 8 with rectangular $25 \mathrm{~cm} \times 25 \mathrm{~cm}$ cross-section covered by $90 \%$ transparency flat grid composed of parallel tungsten 0.5-mm-diameter wires distanced from each other at $5 \mathrm{~mm}$. At the grounded anode bottom is placed Faraday cup 9 allowing control of the electron beam current measured with Rogovsky coil 10.

Figure 2 presents a photograph of the high-voltage pulse generator. Three batteries of capacitors, the capacitance of each battery amounting to $C=10.4 \mu \mathrm{F}$, are charged through resistors $R_{\mathrm{o}}=5 \mathrm{k} \Omega$ and resistors $R=130 \Omega$ up to a voltage ranging from 20 to $100 \mathrm{kV}$. Simultaneously with those three batteries is charged a battery of the discharge power supply its capacitance amounting to $C_{1}=200 \mu \mathrm{F}$. The latter ensures current up to $500 \mathrm{~A}$ of a pulsed glow discharge between the hollow cathode and the hollow anode.

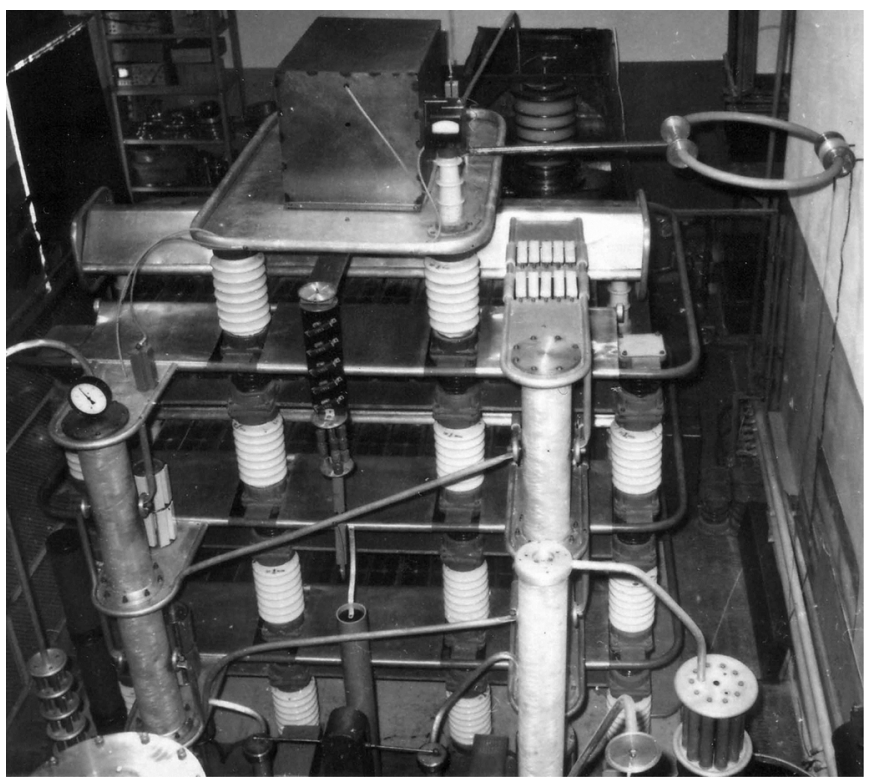

Fig. 2. Photograph of the pulse generator and the electron gun in the background.

The spark-gaps of the pulse generator are located in two sealed dielectric chambers shown in Figure 2. The charging voltage of the spark-gaps is controlled by changing the pressure of the nitrogen supplied to the chambers. When the controlled spark-gaps $\mathrm{SG}_{1}$ is started, two uncontrolled spark-gaps are triggered simultaneously by switching 
overvoltages in the same chamber. As a result, all three batteries $C$ are connected in series and a negative to the grounded vacuum chamber tripled charging voltage is applied to the hollow anode 4 of the electron gun. A voltage equal to the charging voltage is applied to a $0.5-\mathrm{mm}$-wide gap between igniting electrode 6 and additional cathode 5 . Breakdown of this gap initiates ionization of the gas inside the hollow cathode and establishing of a high-current glow discharge between the hollow cathode 3 and the hollow anode 4 . The diaphragm with 6 -cm-diameter central orifice between the hollow cathode and hollow anode reduces losses of fast electrons from the hollow cathode thus allowing the discharge maintenance at the pressure of about $0.01 \mathrm{~Pa}$ in the accelerating gap.

When the discharge plasma appears near emissive grid 7 , electrons from the plasma penetrate through the grid orifices into the accelerating gap. They are accelerated by the applied high voltage $U$, pass through the grid of grounded anode 9 and form a 16-cm-diameter electron beam, which enters Faraday cup 10. As a result, a part of the discharge current is switched from the hollow anode circuit to the accelerating gap.

The width of the accelerating voltage pulse is set by the adjustable delay between the ignition pulses of the controlled spark-gaps $\mathrm{SG}_{1}$ and $\mathrm{SG}_{2}$. When the latter is trigged, two non-controlled spark-gaps are simultaneously triggered in its dielectric chamber. As a result, the voltage applied to the accelerating gap drops to zero, and the remainder of the energy stored in the capacitors is dissipated by the resistors $R$.

To decrease the beam diameter and increase the electron current density, the flat emissive grid was replaced with 16-cm-diameter spherical grid 11 the curvature radius of its surface amounting to $12 \mathrm{~cm}$ (Fig. 1b). The big grounded anode was replaced with spherical anode 12 with a 6-cm-diameter central orifice fastened to an 8-cmdiameter and 12-cm-long hollow cylinder. The cylinder is movable in vertical direction, and the distance between the anode and the grid can be regulated from 10 to $20 \mathrm{~cm}$. To ensure the distance regulation configuration of vacuum chamber 13 was modified. Under the anode cylinder was mounted isolated from the anode 16-cm-diameter and 45cm-long hollow cylindrical collector 14. Current in its circuit measured with Rogovsky coil 15 is equal to the current of the electron beam, which enters through the orifice of anode 12. Current in the circuit of the anode and the chamber is measured with Rogovsky coil 16. For the generation of pulsed electron beams is used the same electrical scheme presented in Figure 1a. Substrate 17 to be exposed to the pulsed electron beam is placed at the bottom of hollow collector 14 . To assess an effective beam diameter, three foils 18-20 distant from each other at $20 \mathrm{~cm}$ can be positioned inside the collector. The upper foil is distant at $15 \mathrm{~cm}$ from the orifice of anode 12 .

\section{Experimental results}

Conditioning of the electron gun electrodes and grids cleaned of impurities and mounted inside the vacuum chamber and the high-voltage feedthrough usually begins
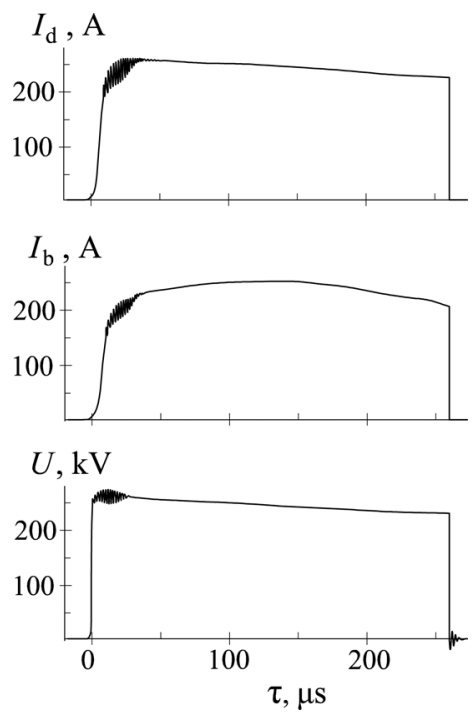

Fig. 3. Oscillograms of discharge current $I_{\mathrm{d}}$, beam current $I_{\mathrm{b}}$ and high voltage $U$.

at minimal amplitude $100 \mathrm{kV}$ of the accelerating voltage pulse and at the pulse width $30 \mu \mathrm{s}$ comparable with the rise-up portions of the glow discharge current pulse and the electron beam current pulse. Further, the width of pulses, following one another in about $30 \mathrm{~s}$, is gradually increased to $100-200 \mu \mathrm{s}$, and then their amplitude is gradually raised. If the breakdown of the accelerating gap occurs before the end of the high-voltage pulse, the width of the next pulse is reduced by a factor of $1.5-2$, and then is gradually increased again.

At the energy of electrons amounting to $250 \mathrm{keV}$, the current pulse amplitude reaches $100 \mathrm{~A}$, and its width before the gap breakdown does not exceed $100 \mu \mathrm{s}$. The maximal density of energy transported by electrons to the surface of the Faraday cup 9 during one pulse amounts to $12.5 \mathrm{~J} \cdot \mathrm{cm}^{-2}$, which is less than the value required for the surface hardening of titanium alloys. Only when the energy of electrons drops to $150 \mathrm{keV}$ and the beam current drops to $50 \mathrm{~A}$, then the pulse width increases to $200 \mu \mathrm{s}$. It can be explained by a decrease in the flow to the accelerating gap from the Faraday cup of the gas and metal vapor produced due to electron bombardment.

After the flat emissive grid (Fig. 1a) is replaced with the spherical grid (Fig. 1b) flow of the gas and metal vapor to the accelerating gap substantially decreases. It allows producing $250-\mu$ s-wide pulses of $250-\mathrm{keV}$ electrons the amplitude of their current reaching $250 \mathrm{~A}$ (Fig. 3) in 10-20 $\mu$ s after the breakdown of the igniting gap between electrodes 5 and 6 (Fig. 1).

Presented in Figure 3 oscillograph traces of the discharge current $I_{\mathrm{d}}$ in the circuit of the hollow cathode, beam current $I_{\mathrm{b}}$ in the circuit of the hollow collector and accelerating voltage $U$ exhibit intensive oscillations within the first $20 \mu$ s of each pulse. The oscillations are caused by instability of the cathode sheath at high rate growth of the glow discharge current, and their frequency amounts to $1-$ $10 \mathrm{MHz}$. During the current growth interval, accelerated electrons bombard anode 12 (Fig. 1b) evaporating the anode surface and ionizing the metal vapor. As a result, the 


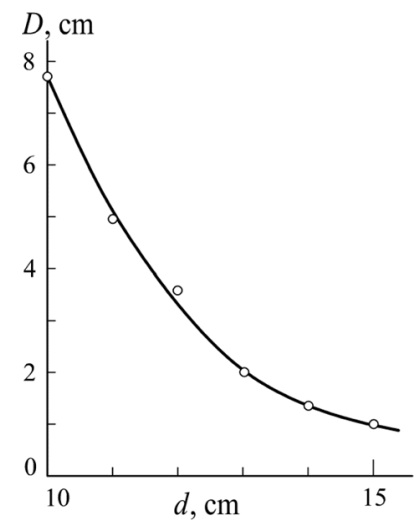

Fig. 4. Dependence of the beam diameter $D$ on the grid-to-anode distance $d$.

6-cm-diameter orifice of the anode is filled with plasma, and in this case, the electron beam is practically formed in a spherical diode with plasma anode, which is transparent for the electrons. The configuration of the electrical field in this diode is favorable for the electron beam compression resulting in the decrease of the beam diameter near the substrate 17 at the hollow collector bottom.

Measurements of the beam prints on $10-\mu m$-thick aluminum foil 20 showed that the beam diameter on the hollow collector bottom decreases from 8 to $1 \mathrm{~cm}$ with increasing the width of the accelerating gap, which is equal to the distance between the center of grid 11 and anode 12 , from 10 to $15 \mathrm{~cm}$ (Fig. 4). Increase in the accelerating gap width results by the Child-Langmuir law [25] in the electron beam current decrease.

On the emissive grid (Fig. 5a) there are six peripheral groups of orifices positioned with the angular interval of $60^{\circ} \mathrm{C}$ between them. Orifices of each group are positioned in one line, each of two neighboring groups contains 6 orifices, and each of the rest four groups contains 5 orifices. At the accelerating gap width of $15 \mathrm{~cm}$ the separate beam components entering the accelerating gap from different orifices of the emissive grid within the period of the current growth trace on upper foil 18 (Fig. 1b) distanced from the grid center at $30 \mathrm{~cm}$ narrow radial lines around a $4-\mathrm{cm}-$ diameter hole burned by the beam (Fig. 5b).

It is possible to distinguish among those lines six groups of scratch-like radial lines each of two neighboring groups containing six lines and each of the rest four groups containing five lines. It means that at the distance of $30 \mathrm{~cm}$ from the grid the separate beam components from different orifices of the grid have not yet been mixed with each other despite the beam diameter diminished about 4 times. Nevertheless, at the bottom of hollow collector 14 (Fig. 1b) distanced from the grid center at $70 \mathrm{~cm}$ the beam components are already mixed with each other and the electron current density is distributed quite homogeneously.

Variation of the beam diameter, which depends on the distance between the grid and the anode, as well as the high-voltage pulse width and amplitude, allows regulating the density of energy transported to the substrate surface per one pulse $w$ from $15 \mathrm{~J} \cdot \mathrm{cm}^{-2}$ to $15 \mathrm{~kJ} \cdot \mathrm{cm}^{-2}$. The latter value was reached at accelerating gap width of $15 \mathrm{~cm}$, when the beam diameter diminished to $1 \mathrm{~cm}$ (Fig. 6).
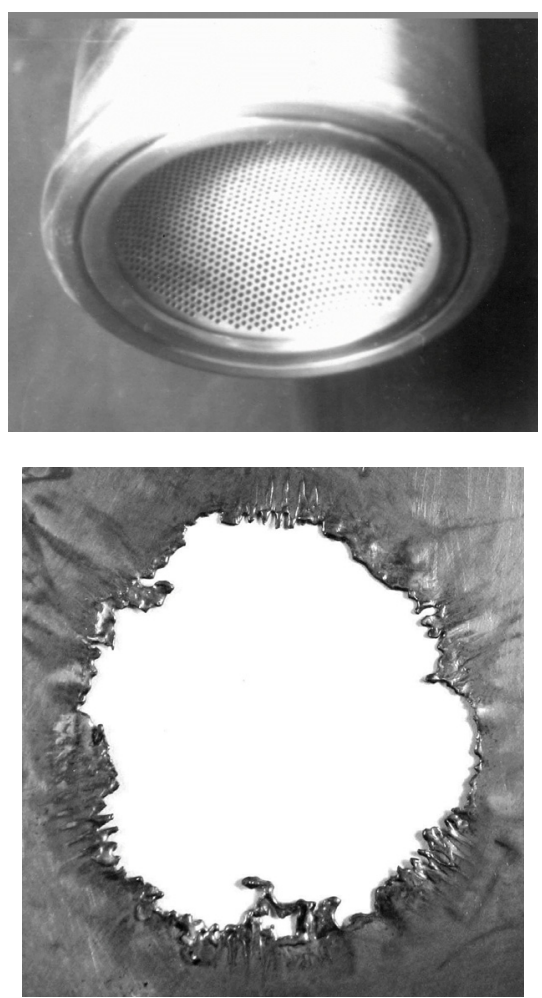

b

Fig. 5. The spherical emissive grid on the cylindrical hollow anode (a) and traces of the beam components around the burned hole on the foil (b).

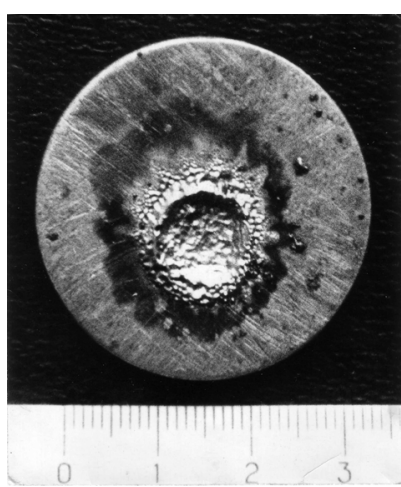

Fig. 6. Print of the 1-cm-diameter beam on a Ti-6Al-4V substrate.

Only at $w$ exceeding $50 \mathrm{~J} \cdot \mathrm{cm}^{-2}$ a complete ablation is realized when a homogeneous surface layer with thickness of several micrometers is removed from the entire surface exposed to the electron beam. At the energy density exceeding $1000 \mathrm{~J} \cdot \mathrm{cm}^{-2}$ the electron beam destroys the substrate surface. For instance at the energy density of $15 \mathrm{~kJ} \cdot \mathrm{cm}^{-2}$ it removes an appreciable amount of material in the form of metal plasma, vapor and droplets thus producing a 3-mm-deep crater on the substrate surface (Fig. 6). 


\section{Discussion}

The data presented above show that compression of the electron beam produced by the electron gun with spherical emissive grid opens the way to a wide-range surface modification of machine parts. It is due to changes of the beam diameter, current, energy of accelerated electrons and pulse width, which allow a wide-range regulation of the energy density transported to the substrate surface per one pulse.

The gun presented in this paper is based on the hollow cathode glow discharge as some previously developed beam sources. For instance, in the electron gun for microwave generation described in [6] plasma of glow discharge with a 300-mm-diameter and 400-mm-long hollow cathode was used as the electron emitter. The plasma was generated at the gas pressure of $\sim 0.7 \mathrm{~Pa}$ inside the cathode. The highvoltage applied between two flat grids spaced by $12 \mathrm{~mm}$ accelerates electrons from the plasma emitter. The grids have 253 pairs of aligned apertures with the diameter of $5.1 \mathrm{~mm}$. At the accelerating voltage of $200 \mathrm{kV}$ and the $100-\mu \mathrm{s}$ width of the pulses, the gun produced electron beams with the current amplitude of $700 \mathrm{~A}$ and diameter of $100 \mathrm{~mm}$.

To reach the above parameters of the beam it was needed to degas the hollow cathode in the vacuum and condition it by glow discharge with the progressively increasing amplitude of the discharge current pulses. For this reason, the mentioned above hollow cathode was made of high-purity molybdenum. All other constructive elements were able to withstand heating up to $300-400^{\circ} \mathrm{C}$. However even after conditioning the cathode a certain probability of the vacuum arc spot occurrence on its surface during the $100-\mu$ s-wide pulse still continued.

Another serious drawback of the above electron gun was a comparatively high gas pressure of $\sim 0.7 \mathrm{~Pa}$ inside the hollow cathode needed to initiate and maintain highcurrent pulsed glow discharge. The reason is a high surface area of the emissive grid, anode and ceramic isolator, which absorb fast electrons oscillating inside the hollow cathode and ionizing the gas. For this reason, a pulsed gas input into the hollow cathode was used.

In the present work, the losses of the fast electrons from the hollow cathode are substantially reduced due to the cathode output diaphragm with 6-cm-diameter central orifice, through which the plasma penetrates into the hollow anode and the spherical emissive grid. It allows the discharge maintenance at the pressure of about $0.01 \mathrm{~Pa}$ in the accelerating gap. Hence, no pulsed gas input into the hollow cathode is needed. Another advantage of the new electron gun is possibility to regulate the beam diameter. It allows variation of transported to the product per one pulse energy density from $15 \mathrm{~J} \cdot \mathrm{cm}^{-2}$ to $15 \mathrm{~kJ} \cdot \mathrm{cm}^{-2}$, which is enough not only for the surface modification, but also for investigation of various materials behavior, when they are exposed to highly dense energy fluxes.

\section{Conclusions}

- Compression of the beam in the electron gun with a plasma emitter of electrons and a spherical emissive grid opens the way to a wide range surface modification of machine parts;

- variation of the distance between the spherical grid and the anode makes it possible to regulate the energy density $w$ transported per one pulse to the substrate in a wide range from $15 \mathrm{~J} \cdot \mathrm{cm}^{-2}$ to $15 \mathrm{~kJ} \cdot \mathrm{cm}^{-2}$;

- successively increasing the energy density from $w=15$ to $100 \mathrm{~J} \cdot \mathrm{cm}^{-2}$, it is possible to harden the machine part surface, then melt the surface layer with further high-speed recrystallization $\left(w \sim 20 \mathrm{~J} \cdot \mathrm{cm}^{-2}\right)$, and finally realize an explosive ablation of the surface layer $\left(w>50 \mathrm{~J} \cdot \mathrm{cm}^{-2}\right)$. At $w>1 \mathrm{~kJ} \cdot \mathrm{cm}^{-2}$ the new developed electron gun makes it possible to investigate behavior of the machine part material exposed to highly dense energy fluxes.

Acknowledgements. This work was financially supported by the Ministry of Education and Science of the Russian Federation in the framework of the state task in the field of scientific activity of MSTU "STANKIN" No 9.7886.2017/6.7.

The work was carried out using the equipment of the Center of collective use of MSTU "STANKIN".

\section{References}

[1] A.V. Hayes, V. Kanarov, B. Vidinsky, Fifty centimeter ion beam source, Rev. Sci. Instrum. 67 (1996) 1638-1641, DOI: $10.1063 / 1.1146907$

[2] A.S. Metel, S.N. Grigoriev, Yu.A. Melnik, V.P. Bolbukov, Broad beam sources of fast molecules with segmented cold cathodes and emissive grids, Instrum. Exp. Tech. 55 (2012) 122-130, DOI: 10.1134/S0020441211060170

[3] D.J. Economou, Fast (tens to hundreds of eV) neutral beams for materials processing, J. Phys. D: Appl. Phys. 41 (2008) 024001, DOI: $10.1088 / 0022-3727 / 41 / 2 / 024001$

[4] S.N. Grigoriev, Yu.A. Melnik, A.S. Metel, M.A. Volosova, Focused beams of fast neutral atoms in glow discharge plasma, J. Appl. Phys. 121 (2017) 223302, DOI: 10.1063/1.4985249

[5] A. Metel, M. Volosova, S. Grigoriev, Yu. Melnik, Products pre-treatment and beam-assisted deposition of magnetron sputtered coatings using a closed cylindrical grid inside a planetary rotation system, Surf. Coat. Technol. 325 (2017) 327-332, DOI: 10.1016/j.surfcoat.2017.06.071

[6] D.M. Goebel, R.M. Watkins, High current, low pressure plasma cathode electron gun, Rev. Sci. Instrum. 71 (1996) 388-398, DOI: 10.1063/1.1150212

[7] R. Ramaseshan, F. Jose, S. Rajagopalan, S. Dash, Preferentially oriented electron beam deposited TiN thin films using focused jet of nitrogen gas, Surf. Eng. 32 (2016) 834-839, DOI: $10.1080 / 02670844.2016 .1159832$

[8] S.N. Grigoriev, Yu.A. Melnik, A.S. Metel, V.V. Panin, V.V. Prudnikov, A compact vapor source of conductive target material sputtered by $3-\mathrm{keV}$ ions at $0.05-\mathrm{Pa}$ pressure, Instrum. Exp. Tech. 52 (2009) 731-737, DOI: 10.1134/ S0020441209050170

[9] S. Veprek, H.-D. Mannling, P. Karvankova, J. Prochazka, The issue of the reproducibility of deposition of superhard nanocomposites with hardness of $\geq 50 \mathrm{GPa}$, Surf. Coat. Technol. 200 (2006) 3876-3885, DOI: 10.1016/j.surfcoat.2004.11.023

[10] C. Ruset, E. Grigore, The influence of ion implantation on the properties of titanium nitride layer deposited by magnetron sputtering, Surf. Coat. Technol. 156 (2002) 159-161, DOI: 10.1016/s0257-8972(02)00121-4 
[11] J. Musil, A. Rajsky, A.J. Bell, J. Matous, M. Cepera, J. Zeman, High-rate magnetron sputtering, J. Vac. Sci. Technol. A 14 (1996) 2187-2191, DOI: 10.1116/1.580045

[12] S.N. Grigoriev, A.S. Metel, S.V. Fedorov, Modification of the structure and properties of high-speed steel by combined vacuum-plasma treatment, Metal Sci. Heat Treat. 54 (2012) 8-12, DOI:10.1007/s11041-012-9447-x

[13] A. Metel, V. Bolbukov, M. Volosova, S. Grigoriev, Yu. Melnik, Equipment for deposition of thin metallic films bombarded by fast argon atoms, Instrum. Exp. Tech. 57 (2014) 345-351, DOI: 10.1134/S0020441214020110

[14] J. Musil, J. Leština, J. Vlček, T. Tölg, Pulsed dc magnetron discharge for high-rate sputtering of thin films, J. Vac. Sci. Technol. A 19 (2001) 420-424, DOI: 10.1116/1.1339018

[15] A. Anders, Tutorial: reactive high power impulse magnetron sputtering, J. Appl. Phys. 121 (2017) 171101, DOI: 10.1063/ 1.4978350

[16] V.N. Zhitomirsky, I. Grimberg, L. Rapoport, R.L. Boxman, N.A. Travitzky, S. Goldsmith, B.Z. Weiss, Bias voltage and incidence angle effects on the structure and properties of vacuum arc deposited TiN coatings, Surf. Coat. Technol. 133134 (2000) 114-120, DOI: 10.1016/S0257-8972(00)00884-7

[17] S.N. Grigoriev, Yu.A. Melnik, A.S. Metel, Gas discharge source of metal vapor and fast gas atoms, Instrum. Exp. Tech. 56 (2013) 358-364, DOI: 10.1134/S0020441213030044

[18] A.S. Metel, Yu.A. Melnik, A high-current plasma emitter of electrons based on a glow discharge with a multirod electrostatic trap, Instrum. Exp. Tech. 56 (2013) 317-324, DOI: 10.1134/S0020441213020164

[19] A.S. Metel, Beams of fast neutral atoms and molecules in low-pressure gas-discharge plasma, Plasma Phys. Rep. 38 (2012) 254-262, DOI: 10.1134/S1063780X12020080

[20] I. Beilis, Y. Koulik, Y. Yankelevich, D. Arbilly, R. Boxman, Thin-film deposition with refractory materials using a vacuum arc, IEEE Trans. Plasma Sci. 43 (2015) 23232328, DOI: 10.1109/TPS.2015.2432577

[21] K. Tanaka, A. Anders, Temporal evolution of ion energy distribution functions and ion charge states of $\mathrm{Cr}$ and $\mathrm{Cr}-\mathrm{Al}$ pulsed arc plasmas, J. Vac. Sci. Technol. A 323 (2015) 061301, DOI: $10.1116 / 1.4926750$
[22] A. Metel, V. Bolbukov, M. Volosova, S. Grigoriev, Yu. Melnik, Source of metal atoms and fast gas molecules for coating deposition on complex shaped dielectric products, Surf. Coat. Technol. 225 (2013) 34-39, DOI: 10.1016/j. surfcoat.2013.03.013

[23] A.S. Metel, S.N. Grigoriev, M.A. Volosova, V.P. Bolbukov, Yu.A. Melnik, Role of electrostatic and magnetic electron confinement in a hollow-cathode glow discharge in a nonuniform magnetic field, Plasma Phys. Rep. 41 (2015) 188-197, DOI: 10.1134/S1063780X14120058

[24] A.S. Metel, S.N. Grigoriev, M.A. Volosova, Yu.A. Melnik, Magnetron sputtering device with generation of pulsed beams of high-energy gas atoms, Instrum. Exp. Tech. 60 (2017) 290-296, DOI: 10.1134/S1063780X14120058

[25] S. Grigoriev, A. Metel, Plasma- and beam-assisted deposition methods, in: A.A. Voevodin, D.V. Shtansky, E.A. Levashov, J.J. Moore (Eds.), Nanostructured thin films and nanodispersion strengthened coatings, Kluwer Academic Publishers, Boston, Dordrecht, London, 2004, pp. 147-154, DOI: $10.1007 / 1-4020-2222-0 \quad 14$

[26] I. Langmuir, The interaction of electron and positive ion space charges in cathode sheaths, Phys. Rev. 33 (1929) 954989, DOI: 10.1103/PhysRev.33.954

[27] V.A. Shulov, V.I. Engelko, I.V. Kovalev, G. Mueller, Crater creation on the surface of refractory alloy parts during intense pulsed ion and electron beam irradiation, Proceedings of 7 th Int. Conf. on Modification of Materials with Particle Beams and Plasma Flows, Tomsk, Russia, 2004, pp. 289-292, http://www.congress-2006.hcei.tsc.ru/cat/ proc 2004/13/Paper 7 071.pdf

[28] A.S. Metel, Effect of ionization in the cathode layer on the characteristics of a Penning discharge. I. Hollow cathode discharge, Sov. Phys. - Tech. Phys. 30 (1985) 1133-1136

[29] V.I. Kolobov, A.S. Metel, Glow discharges with electrostatic confinement of fast electrons, J. Phys. D: Appl. Phys. 48 (2015) 233001, DOI: 10.1088/0022-3727/48/23/233001

[30] I. Smurov, M. Doubenskaia, S. Grigoriev, A. Nazarov, Optical Monitoring in Laser Cladding of Ti6Al4V, J. Therm. Spray Technol. 21 (2012) 1357-1362, DOI: 10.1007/s11666012-9808-4

Cite this article as: A.S. Metel, Compression of pulsed electron beams for material tests, Mechanics \& Industry 18, 708 (2017) 